Article

\title{
Docosahexaenoic Acid (DHA) Bioavailability in Humans after Oral Intake of DHA-Containing Triacylglycerol or the Structured Phospholipid AceDoPC ${ }^{\circledR}$
}

\author{
Mayssa Hachem ${ }^{1,+} \oplus$, Houda Nacir ${ }^{1,+}$, Madeleine Picq ${ }^{1,+}$, Mounir Belkouch ${ }^{1}$, \\ Nathalie Bernoud-Hubac ${ }^{1}$ (D) Anthony Windust ${ }^{2}$, Laure Meiller ${ }^{1,2}$, Valerie Sauvinet ${ }^{1,2}{ }^{\mathbb{D}}$, \\ Nathalie Feugier ${ }^{3,4}$, Stephanie Lambert-Porcheron ${ }^{3,4}$, Martine Laville ${ }^{1,3,4}$ and \\ Michel Lagarde ${ }^{1, *}$ \\ 1 Univ-Lyon, CarMeN Laboratory, Inserm UMR 1060, Inra UMR 1397, IMBL, INSA-Lyon, 69100 Villeurbanne, \\ France; mhachem@amityuniversity.ae (M.H.); houda.nacir@yahoo.fr (H.N.); \\ madeleine.picq@insa-lyon.fr (M.P.); mbelkouch@yahoo.fr (M.B.); \\ nathalie.bernoud-hubac@insa-lyon.fr (N.B.-H.); laure.meiller@chu-lyon.fr (L.M.); \\ valerie.sauvinet@chu-lyon.fr (V.S.); martine.laville@chu-lyon.fr (M.L.) \\ 2 National Research Council Canada, Ottawa, ON K1A 0R6, Canada; ajwindust@gmail.com \\ 3 Hospices Civils de Lyon, Groupement Hospitalier Sud, 69310 Pierre-Bénite, France; \\ nathalie.feugier@chu-lyon.fr (N.F.); stephanie.lambert-porcheron@chu-lyon.fr (S.L.-P.) \\ 4 CRNH Rhône-Alpes, CENS, 69310 Pierre-Bénite, France \\ * Correspondence: michel.lagarde@insa-lyon.fr \\ + Co-first authors.
}

Received: 11 November 2019; Accepted: 15 January 2020; Published: 18 January 2020

\begin{abstract}
AceDoPC ${ }^{\circledR}$ is a structured glycerophospholipid that targets the brain with docosahexaenoic acid (DHA) and is neuroprotective in the experimental ischemic stroke. AceDoPC ${ }^{\circledR}$ is a stabilized form of the physiological 2-DHA-LysoPC with an acetyl group at the sn1 position; preventing the migration of DHA from the $s n 2$ to $s n 1$ position. In this study we aimed to know the bioavailability of ${ }^{13} \mathrm{C}$-labeled DHA after oral intake of a single dose of ${ }^{13} \mathrm{C}$-AceDoPC ${ }^{\circledR}$, in comparison with ${ }^{13} \mathrm{C}$-DHA in triglycerides (TAG), using gas chromatography/combustion/isotope ratio mass spectrometry (GC/C/IRMS) to assess the ${ }^{13} \mathrm{C}$ enrichment of DHA-containing lipids. ${ }^{13} \mathrm{C}$-DHA enrichment in plasma phospholipids was significantly higher after intake of AceDoPC ${ }^{\circledR}$ compared with TAG-DHA, peaking after $24 \mathrm{~h}$ in both cases. In red cells, ${ }^{13} \mathrm{C}$-DHA enrichment in choline phospholipids was comparable from both sources of DHA, with a maximum after $72 \mathrm{~h}$, whereas the ${ }^{13} \mathrm{C}$-DHA enrichment in ethanolamine phospholipids was higher from AceDoPC ${ }^{\circledR}$ compared to TAG-DHA, and continued to increase after $144 \mathrm{~h}$. Overall, our study indicates that DHA from AceDoPC ${ }^{\circledR}$ is more efficient than from TAG-DHA for a sustained accumulation in red cell ethanolamine phospholipids, which has been associated with increased brain accretion.
\end{abstract}

Keywords: plasma phospholipids; brain; gas chromatography combustion isotope ratio mass spectrometry

\section{Introduction}

Docosahexaenoic acid (DHA)/22:6n-3 is the long-chain polyunsaturated n-3 fatty acid (n-3 PUFA) which specifically accumulates into the brain where it plays a crucial role for the development and function [1]. Indeed, DHA is required for brain development from fetus to adult, and for cognition and visual acuity [2]. It is involved in brain development such as synaptogenesis, neurogenesis, neuronal 
differentiation [3], and maintenance of membrane fluidity [4]. In addition, brain DHA content is altered in neurodegenerative diseases, particularly in Alzheimer's disease [5,6]. DHA synthesis from oral intake of its essential precursor $\alpha$-linolenic acid (18:3n-3) is only $1 \%$ in men and 1-3\% in women [7]. Due to this low level of synthesis, dietary pre-formed DHA is the preferred source of DHA to improve brain DHA accretion.

It is known that DHA comes from blood plasma through crossing the blood-brain barrier (BBB), both as a non-esterified fatty acid and as esterified in lyso-phosphatidylcholine (lysoPC). However, several studies have shown that, although a slower uptake of DHA was observed from DHA-containing lysoPC, a stronger DHA accumulation into the brain was found on a long term [8,9], whereas the brain uptake of DHA is faster but more limited from non-esterified DHA [10,11]. Indeed, DHA esterified at the $s n 2$ position of lysoPC more efficiently crosses a re-constituted BBB than non-esterified DHA [12]. This has been corroborated by more recent studies showing that BBB expresses the specific binding protein Mfsd2a to facilitate this transfer [13], and that an oral intake of DHA-containing lysoPC is more efficient than non-esterified DHA to increase the brain DHA content and the memory [9]. It is noteworthy that the brain uptake of other unsaturated fatty acids, especially arachidonic acid, which is the second most abundant after DHA, also is most efficient when esterified in lysoPC [14].

However, DHA esterified at the $s n 2$ position of lysoPC, supposed to be its physiological position within phosphoglycerides, rapidly migrates to the $s n 1$ position [15]. We then structured such a lysoPC to prevent this migration, by acetylating the $s n 1$ position [16]. The resulting structured phospholipid: 1-acetyl, 2-docosahexaenoyl-glycerophosphocholine has been named AceDoPC ${ }^{\circledR}$. This compound affords more neuroprotection in a post-ischemic stroke model than does non-esterified DHA [17], and DHA incorporation into brain tissues is greater with AceDoPC than with equimolar concentrations of non-esterified DHA or of PC DHA [18]. On the other hand, additional findings showed that AceDoPC ${ }^{\circledR}$ inhibits lipopolysaccharide-induced neuro-inflammation in microglial cells through interleukin-6 signaling [19], and activates neurogenesis, but not astrogenesis, from nerve stem cells [20]. In light of this potential, it was of interest to investigate the bioavailability of DHA in humans from oral intake of AceDoPC ${ }^{\circledR}$ compared to a usual source such as TAG-DHA.

\section{Materials and Methods}

\subsection{Human Volunteers}

Three healthy men between 60 to 70 years old, with no cognitive defects, were selected. Their body mass index was between 20 to $30 \mathrm{Kg} / \mathrm{m}^{2}$. In whole blood of fasting subjects, glycaemia was less than $7 \mathrm{mmol} / \mathrm{L}$, total cholesterol was less or equal to $7 \mathrm{mmol} / \mathrm{L}$, triglycerides level was less than $1.7 \mathrm{mmol} / \mathrm{L}$, and hemoglobin was more than $130 \mathrm{~g} / \mathrm{L}$. All subjects gave their informed consent for inclusion before participating in the study.

\subsection{Experimental Procedure}

The research was conducted at the clinical research center from Rhône-Alpes Research Center for Human Nutrition (CRNH-RA) under the Clinical Trial Number NCT02168738. The Sponsor was the Hospices Civils de Lyon, and the agreement was obtained from the legal authorities, after approvement by the local ethics committee. This was a double-blind randomized study with a crossover use of two sources: ${ }^{13} \mathrm{C}$-AceDoPC and TAG- ${ }^{13} \mathrm{C}$-DHA. Each source contained $50 \mathrm{mg}$ of ${ }^{13} \mathrm{C}-\mathrm{DHA}$ that was ingested after $12 \mathrm{~h}$ of fasting, as an alcoholic solution on a piece of bread. The blood sampling ( $36 \mathrm{~mL}$ in total) started before the DHA ingestion (T0), and after 1 (T1), 3 (T3), 6 (T6), 24 (d1), 72 (d3), and 144 (d6) hours, of the oral intake. A wash-out of 120 days between each source was applied to avoid or minimize ${ }^{13} \mathrm{C}$ labeling of red blood cells from the first intake. 


\subsection{Synthesis of Labeled DHA Sources}

\subsection{1. ${ }^{13} \mathrm{C}$-AceDoPC Synthesis}

The synthesis of labeled AceDoPC with ${ }^{13} \mathrm{C}$-DHA was similar to that of $\left[{ }^{14} \mathrm{C}\right]$-AceDoPC as previously described [18], using a DHA ester form, $\mathrm{U}^{13} \mathrm{C}-\mathrm{DHA}$ methyl ester (provided by Dr. Anthony Windust's lab) uniformly labeled with carbon 13. The purity of the synthesized product was checked by High Performance Liquid Chromatography (HPLC), and ${ }^{13} \mathrm{C}$ Nuclear Magnetic Resonance (NMR). Finally, DHA was analyzed by Gas Chromatography (GC) and the ${ }^{13} \mathrm{C}$ enrichment was checked by GC/mass spectrometry (MS), showing uniformly labeled DHA.

\subsubsection{Production of ${ }^{13} \mathrm{C}$-DHA-Containing Triacylglycerol}

${ }^{13}$ C-TAG was produced by growing a microalgae (Crypthecodinium cohnii) strain (ATCC-30772 American Type Culture Collection) in a defined medium by Nestlé industry (Tours, France). All the products came from Sigma or Riedel-deHaën. The microalgae were developed during several days in a specific medium with salt and water in dark conditions. Microalgae were transferred in a starting medium, at $\mathrm{pH} 6.5$ and $27^{\circ} \mathrm{C}$, containing $1{ }^{13} \mathrm{C}$-acetate. The biomass was collected after 20 days of microalgae growing.

${ }^{13}$ C-DHA-TAG was harvested from the cells by centrifugation. The biomass was then freeze-dried, and lipids were extracted with hexane/isopropanol/water 5:5:1 ( $v / v / v)$. Lipids were separated by HPLC, using a normal phase silica column $(21 \times 250 \mathrm{~mm} ; 10 \mu \mathrm{m})$. The solvent system used was a gradient consisting of hexane/2-propanol (55:4, v/v) (solvent A) to hexane/isopropanol/water (60/120/20, v/v/v) (solvent B) with a flow rate of $30 \mathrm{~mL} / \mathrm{min}$. Neutral lipids were eluted and collected between 0 and $8 \mathrm{~min}$. The fatty acid composition of TAG was obtained by GC showing that DHA represented $20 \%$ of total fatty acids in TAG. Analysis of proton spectrum of ${ }^{13} \mathrm{C}-\mathrm{TAG}$ showed high purity of the samples according to NMR Bruker $400 \mathrm{MHz}$ experiment (10 mg of samples prepared in $0.75 \mathrm{~mL} \mathrm{CDCL}{ }_{3}$ ). The GC/MS analysis confirmed eleven ${ }^{13} \mathrm{C}$ within one molecule of DHA. The non-toxicity for human administration was checked by pharmacists from Hospices Civils de Lyon.

\subsection{Blood Red Cells and Plasma Preparation}

Blood samples were collected in tubes containing citrate-dextrose and the red cells and platelet-poor-plasma were obtained as described previously [21]. Plastic tubes containing whole blood were centrifuged at $200 \times \mathrm{g}$ for $15 \mathrm{~min}$ at $4{ }^{\circ} \mathrm{C}$ to obtain platelet-rich plasma (PRP) and the red blood cells pellet. This PRP was acidified to $\mathrm{pH} 6.4$ with citric acid to prevent platelet activation and centrifuged at $900 \times g$ for $12 \mathrm{~min}$ at $4{ }^{\circ} \mathrm{C}$ to pellet platelets and get the platelet poor plasma (PPP) in the supernatant. This PPP was then centrifuged at $2000 \times g$ for $10 \mathrm{~min}$ at $4{ }^{\circ} \mathrm{C}$ to eliminate the remaining platelets, and the plasma supernatant was added with $5 \times 10^{-5} \mathrm{M}$ butyl hydroxyl-toluene (BHT) as an antioxidant, and frozen at $-80{ }^{\circ} \mathrm{C}$ until purification of lipids. Blood red cells/erythrocytes, from the first $200 \times g$ pellet, were diluted in Tyrode-HEPES buffer and centrifuged at $100 \times \mathrm{g}$ for $10 \mathrm{~min}$ at $4{ }^{\circ} \mathrm{C}$ to remove contaminating white cells. After removing the supernatant, red blood cells were diluted with $9 \% \mathrm{NaCl}$ and centrifuged at $2000 \times g$ for $10 \mathrm{~min}$ at $4{ }^{\circ} \mathrm{C}$. This was repeated once and Tyrode-HEPES was added to red cells, in presence of $5 \times 10^{-5} \mathrm{M} \mathrm{BHT}$ as an antioxidant, and stored at $-80^{\circ} \mathrm{C}$.

\subsection{Extraction and Separation of Lipids from Red Cells and Plasma}

Total lipids were extracted from red cells and plasma according to Bligh and Dyer. Internal standards (1,2-diheptadecanoyl-glycerophosphocholine and 1,2-diheptadecanoyl-glyceroethanolamine) were added to samples before lipid extraction for quantification. Lipid classes were separated by thin-layer chromatography (TLC) with first diethylether/methanol (90:10, v/v) as the mobile phase to elute nonpolar lipids. Then, total phospholipids were extracted from the origin, or phosphatidylethanolamine (PE) and phosphatidylcholine (PC) were 
separated with chloroform/methanol/water $(63: 27: 4, v / v / v)$. Total phospholipids or PC and PE were scraped off the plate and treated for $90 \mathrm{~min}$ with boron trifluoride in methanol/toluene $(50: 50, v / v)$ to obtain fatty acid methyl esters.

\subsection{Quantification of ${ }^{13} \mathrm{C}$ by Gas Chromatography Combustion-Isotope Ratio Mass Spectrometry (GC-C-IRMS)}

The ${ }^{13} \mathrm{C}$ enrichment was measured by GC-C-IRMS (gas chromatography-combustion isotope ratio mass spectrometry) (Isoprime; Elementar UK Ltd, Cheade SK8 6PT, UK.) [22]. The sample was injected into a gas chromatograph (model GC6890, Agilent Technologies, Palo Alto, CA, United States) equipped with a fused-silica column (SP2380, $30 \mathrm{~m} \times 0.25 \mathrm{~mm} \times 0.20 \mu \mathrm{m}$ film thickness, Supelco). Helium was used as the carrier gas. Injection $(1 \mu \mathrm{L})$ was performed in split less mode at $250{ }^{\circ} \mathrm{C}$, with a split less time of $1 \mathrm{~min}$. DHA was separated at constant flow $\left(1.2 \mathrm{~mL} \mathrm{~min}^{-1}\right)$ with the following oven program: (a) $100^{\circ} \mathrm{C}$ for $1 \mathrm{~min}$; (b) increase at a rate of $25^{\circ} \mathrm{C} \mathrm{min}-1$ to $175^{\circ} \mathrm{C}$; (c) hold at $175^{\circ} \mathrm{C}$ for $5.3 \mathrm{~min}$; (d) increase at a rate of $4{ }^{\circ} \mathrm{C} \mathrm{min}^{-1}$ to $250^{\circ} \mathrm{C}$. The GC effluent was diverted to a flame ionization detector until the elution of the target peak. The effluent from the gas chromatograph was then switched into a copper oxide furnace maintained at $850{ }^{\circ} \mathrm{C}$ which produced $\mathrm{CO}_{2}$ and water from the sample. Water and $\mathrm{CO}_{2}$ passed through Nafion tubing, where water was removed, while $\mathrm{CO}_{2}$ was transferred to the IRMS instrument via an open-split interface. Before and after the $\mathrm{CO}_{2}$ peak arising from sample combustion, a reference $\mathrm{CO}_{2}$ gas calibrated against PDB was sequentially injected in the IRMS instrument for $30 \mathrm{~s}$, where PDB is the Pee Dee Belemnite international standard $\left(\left({ }^{13} \mathrm{C} /{ }^{12} \mathrm{C}\right)_{\mathrm{PDB}}=0.0112372\right)$. The different isotopomers were collected onto three different collectors at mass-to-charge ratio $(\mathrm{m} / \mathrm{z}) 44$ (main ion: $\left.{ }^{12} \mathrm{C}^{16} \mathrm{O}^{16} \mathrm{O}\right), 45\left({ }^{13} \mathrm{C}^{16} \mathrm{O}^{16} \mathrm{O},{ }^{12} \mathrm{C}^{16} \mathrm{O}^{17} \mathrm{O}\right.$ ), and $46\left({ }^{12} \mathrm{C}^{17} \mathrm{O}^{17} \mathrm{O}\right.$, ${ }^{12} \mathrm{C}^{16} \mathrm{O}^{18} \mathrm{O},{ }^{13} \mathrm{C}^{16} \mathrm{O}^{17} \mathrm{O}$ ). Ions at $\mathrm{m} / \mathrm{z} 44,45$, and 46 were continuously recorded until the return of the 44 signal to the baseline value. Isotopomers at $\mathrm{m} / \mathrm{z} 44$ and 45 were measured, leading to the ${ }^{13} \mathrm{C} /{ }^{12} \mathrm{C}$ ratio. The ${ }^{13} \mathrm{CO}_{2} /{ }^{12} \mathrm{CO}_{2}$ ratios of samples were expressed as $\delta^{13} \mathrm{C} \%$ relative to PDB:

$$
\delta^{13} C_{\text {sample }}=\left[\frac{\left(\frac{13 C}{{ }^{12} C}\right)_{\text {sample }}}{\left(\frac{13 C}{{ }^{12} C}\right)_{\mathrm{PDB}}}-1\right] \times 1000
$$

To take into account the difference of labelling of the DHA between ${ }^{13} \mathrm{C}$-AceDoPC $\left(22{ }^{13} \mathrm{C}\right.$ atoms) and ${ }^{13} \mathrm{C}$-TAG $\left(11{ }^{13} \mathrm{C}\right.$ atoms) results were finally expressed in mole percent excess (MPE) calculated from the Atom\%:

$$
\text { At } \%=\left[100 \times\left({ }^{13} \mathrm{C} /{ }^{12} \mathrm{C}\right) \mathrm{PDB} \times\left(0.001 \times \delta{ }^{13} \mathrm{C}_{\text {sample }}+1\right)\right] /\left[1+\left({ }^{13} \mathrm{C} /{ }^{12} \mathrm{C}\right) \mathrm{PDB} \times\left(0.001 \times \delta{ }^{13} \mathrm{C}_{\text {sample }}+1\right)\right.
$$

\subsection{Measures of Quality Control}

A quality control standard including DHA compound (Mix 37 from Supelco) was injected before and after each batch of analyses. Less than $4.8 \%$ variation was observed for ${ }^{13} \mathrm{C}$-DHA enrichment during the study period.

\subsection{Statistical Analysis}

Results are means \pm SEM values of $n=3$. Data with different signs are significantly different at $p<0.05$, according to the Student $t$ test.

\section{Results}

\section{1. ${ }^{13} \mathrm{C}-$-DHA Incorporation into Plasma Phospholipids}

After separation of total phospholipids fraction by TLC, FAMEs were analyzed by GC-C-IRMS as described in Materials \& Methods. The ${ }^{13} \mathrm{C}$ enrichment in DHA was calculated and reported as the 
amount of ${ }^{13} \mathrm{C}$-DHA content in the analyzed samples (Figure 1). An increase from both DHA sources $\left({ }^{13} \mathrm{C}\right.$-AceDoPC and ${ }^{13} \mathrm{C}$-DHA-TAG) started after $3 \mathrm{~h}$ of DHA intake, but was substantial after $6 \mathrm{~h}$, and peaked after $24 \mathrm{~h}$. However, the ${ }^{13} \mathrm{C}$-DHA peak was 2-fold higher from AceDoPC (5386 pmol/mL) compared to TAG-DHA (3247 pmol/mL). After peaking, the ${ }^{13} \mathrm{C}$ enrichment in DHA decreased at $72 \mathrm{~h}$ from both sources but remained significantly different. This decrease continued until $144 \mathrm{~h}$, but no more significance between the two sources could be seen. The statistical significance could then be observed after $24 \mathrm{~h}$ and $72 \mathrm{~h}$.

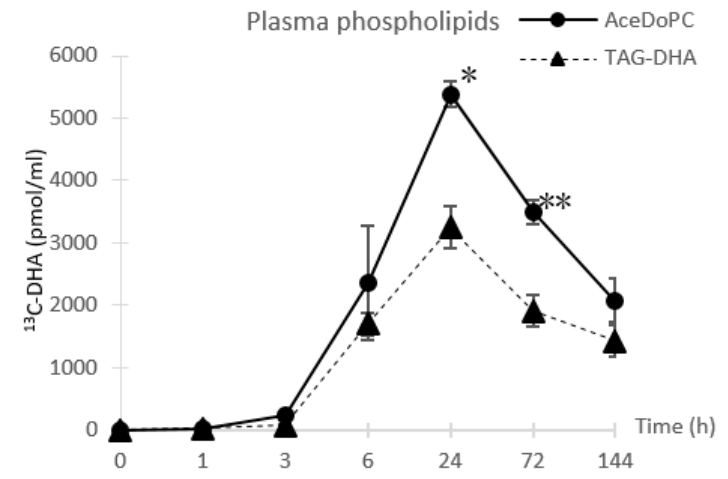

(A)

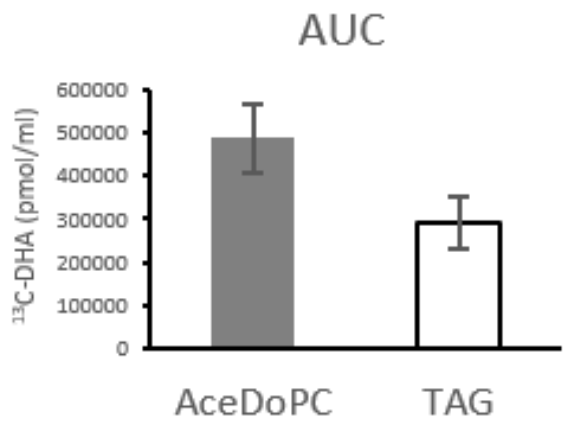

(B)

Figure 1. ${ }^{13} \mathrm{C}$-DHA in plasma phospholipids from AceDoPC compared to TAG-DHA after 50 mg DHA intake in both esterified forms, at different times post-intake (A). Results are expressed in pmol of ${ }^{13}$ C-DHA per $\mathrm{mL}$ of plasma, presented as means \pm SEM from three values. (B) represents area under curves (AUC) from Figure 1A. Stars indicate significant differences within each time, according to the student $t$ test.

\section{2. ${ }^{13} \mathrm{C}$-DHA Incorporation into Red Cells PC and PE}

${ }^{13} \mathrm{C}$-DHA appeared in red blood cells (phosphatidylcholines + phosphatidylethanolamines: PC $+\mathrm{PE}$ ) after $6 \mathrm{~h}$, and increased linearly till $72 \mathrm{~h}$, then plateauing at $144 \mathrm{~h}$, although ${ }^{13} \mathrm{C}$-DHA tended to decrease from TAG-DHA while tending to increase from AceDoPC. (Figure $2 \mathrm{~A})$. The ${ }^{13} \mathrm{C}-\mathrm{DHA}$ appearance into PC exhibited a peak at $72 \mathrm{~h}$ and decreased at $144 \mathrm{~h}$ (Figure 2B). No significant differences were found for these kinetics for both sources. When studying the accumulation of ${ }^{13} \mathrm{C}-\mathrm{DHA}$ into PE, it tended to plateauing at $144 \mathrm{~h}$ from ${ }^{13} \mathrm{C}$-DHA-TAG whereas it sharply increased at this latter time from ${ }^{13} \mathrm{C}$-AceDoPC, with around twice as much of ${ }^{13} \mathrm{C}$-DHA from AceDoPC (Figure $2 \mathrm{C}$ ). This strongly suggests that the transfer of DHA over time, which is expected from PC to PE, was more important from AceDoPC than from TAG-DHA.

Overall, Figure 2 shows a transfer over time of DHA from PC to PE, which was predominant when the oral source was AceDoPC compared to TAG-DHA. 

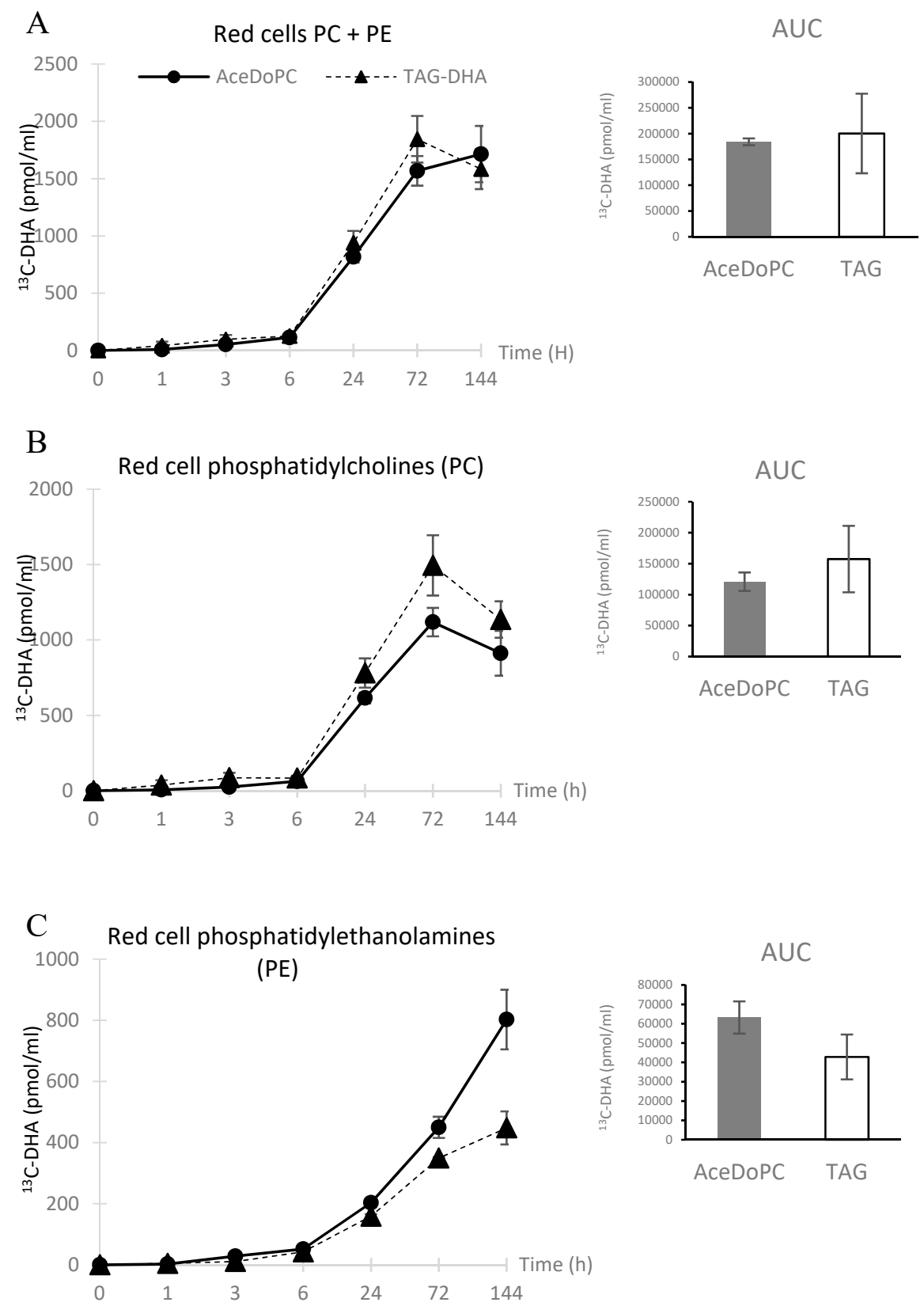

Figure 2. ${ }^{13} \mathrm{C}$-DHA in red cell phospholipids after intake of ${ }^{13} \mathrm{C}-\mathrm{DHA}$ esterified in either AceDoPC or TAG. Fifty milligrams of ${ }^{13} \mathrm{C}$-DHA source were ingested, and blood samples collected at the different times shown in figures. PE \& PC were separated as described in Materials \& Methods. Results are expressed in pmol of ${ }^{13} \mathrm{C}$-DHA per $\mathrm{mL}$ of blood, presented as $\pm \mathrm{SEM}$ from three values. (A) relates to ${ }^{13} \mathrm{C}$-DHA incorporation into red cell PC+PE. $(\mathrm{B}, \mathrm{C})$ relate to separate phospholipids PC and $\mathrm{PE}$, respectively.

\section{Discussion}

It is usually considered that TAG are hydrolyzed at the intestinal level, followed by the absorption of unesterified fatty acids and the remaining 2-acyl-glycerol. Therefore, the DHA bioavailability from TAG-DHA will be affected by its position within the TAG. Considering AceDoPC, DHA being exclusively at the $s n 2$ position, we might expect its release by phospholipase $\mathrm{A}_{2}$, as it occurs from classical phospholipids, except if AceDoPC sufficiently mimicks a lysoPC to be absorbed without hydrolysis. ${ }^{13} \mathrm{C}-\mathrm{DHA}$ bioavailability from TAG-DHA and AceDoPC should then be different. The results obtained 
above suggest a higher bioavailability of ${ }^{13} \mathrm{C}$-DHA from the latter form, with an almost double amount of ${ }^{13} \mathrm{C}$-DHA in plasma phospholipids.

The kinetics of ${ }^{13} \mathrm{C}-\mathrm{DHA}$ accumulation in red cell phospholipids compared to plasma clearly show a transfer from the latter to the former. In a previous study with ${ }^{13}$ C-DHA-TAG only, we found there was still increased accumulation in red cell phospholipids after 3 days [23]. Also, in another study looking at the ${ }^{13} \mathrm{C}$-DHA distribution from a single oral intake of phosphatidylcholine $\left({ }^{13} \mathrm{C}\right.$-DHA-PC) in three human volunteers [24], the last time analysis was after 3 days which did not allow to discriminate between PC and PE accumulation kinetics in red cells. In the current study, the last blood withdrawing was done after 6 days, which reveals a plateau in DHA accumulation in total red cell phospholipids and a different kinetics between PC and PE. Interestingly, ${ }^{13} \mathrm{C}$-DHA in PC peaked after 3 days and started to decrease at 6 days while it still continued to accumulate into PE. Such a difference in the incorporation of ${ }^{13} \mathrm{C}$-DHA within erythrocyte $\mathrm{PE}$ is in agreement with the preferential accumulation of DHA into brain PE after dietary intake [25]. Although ${ }^{13} \mathrm{C}$-DHA from TAG-DHA started to plateau after 3 days, it continued to rise from AceDoPC. This suggests that AceDoPC would better promote the brain DHA accretion, as erythrocyte DHA is considered as a marker of brain DHA [26]. This agrees with the observation that AceDoPC, injected i.v. to rats, is efficient to bring DHA to the brain [18], if we speculate that part of this transporter crosses the intestine. Alternatively, it may be considered that AceDoPC might acetylate intestinal targets in an aspirin-like activity [27], then releasing lysoPC-DHA for easily crossing the intestine like other lysoPC from PC-DHA hydrolysis. The recent paper from Sugasini et al. is in favor of this easy crossing [9].

\section{Conclusions}

In summary, oral intake of AceDoPC, even as a single moderate dose $(50 \mathrm{mg})$ would facilitate DHA accumulation in human red cell PE, which is a marker of brain DHA accretion, likely because of a similar structure to lysoPC-DHA. Showing human brain enrichment itself with DHA from dietary AceDoPC would require other approaches, such as brain imaging after intake of appropriately labeled AceDoPC.

Author Contributions: Conceptualization: M.P., N.B.-H., M.L. (Martine Laville), M.L. (Michel Lagarde). Methodology: M.H., H.N., M.P., M.B., N.B.-H., L.M., V.S., M.L. (Martine Laville), M.L. (Michel Lagarde). Formal analysis: M.H., H.N., M.P., M.B., N.B.-H., L.M., V.S. Resources: M.P., A.W., N.F., S.L.-P. Writing-original draft preparation: H.N., M.L. (Michel Lagarde). Writing-review and editing: M.H., H.N., M.B., N.B.-H., L.M., V.S., M.L. (Martine Laville), M.L., S.L.-P., M.L. (Michel Lagarde). Supervision: M.L. (Michel Lagarde). Project administration: M.L. (Martine Laville), M.L. (Michel Lagarde). Funding acquisition: M.L. (Martine Laville), M.L. (Michel Lagarde). All authors have read and agreed to the published version of the manuscript.

Funding: This research was funded by the French National Agency for Research (ANR) for the grant "Neuroprotect" (2008-2012).

Acknowledgments: The Authors thank, Nestle for providing ${ }^{13} \mathrm{C}-\mathrm{DHA}-\mathrm{TAG}$, and Polaris for funding the PhD thesis salary of MH. We also wish to thank the volunteers, all the nursing and medical staff of the Rhône-Alpes Research Center for Human Nutrition, and the clinical research department of Hospices Civils de Lyon for trials sponsoring and monitoring.

Conflicts of Interest: The authors declare no conflict of interest.

\section{References}

1. Crawford, M.A.; Doyle, W.; Leaf, A.; Leighfield, M.; Ghebremeskel, K.; Phylactos, A. Nutrition and neurodevelopmental disorders. Nutr. Health 1993, 9, 81-97. [CrossRef]

2. Uauy, R.; Hoffman, D.R. Essential fat requirements of preterm infants. Am. J. Clin. Nutr. 2000, 71, $245 \mathrm{~S}-250 \mathrm{~S}$. [CrossRef]

3. Gharami, K.; Das, M.; Das, S. Essential role of docosahexaenoic acid towards development of a smarter brain. Neurochem. Int. 2015, 89, 51-62. [CrossRef]

4. Pinot, M.; Vanni, S.; Pagnotta, S.; Lacas-Gervais, S.; Payet, L.A.; Ferreira, T.; Gautier, R.; Goud, B.; Antonny, B.; Barelli, H. Lipid cell biology. Polyunsaturated phospholipids facilitate membrane deformation and fission by endocytic proteins. Science 2014, 345, 693-697. [CrossRef] [PubMed] 
5. Cunnane, S.C.; Schneider, J.A.; Tangney, C.; Tremblay Mercier, J.; Fortier, M.; Bennett, D.A.; Morris, M.C. Plasma and brain fatty acid profiles in mild cognitive impairment and Alzheimer's disease. J. Alzheimers Dis. 2012, 29, 691-697. [CrossRef] [PubMed]

6. Belkouch, M.; Hachem, M.; Elgot, A.; Lo Van, A.; Picq, M.; Guichardant, M.; Lagarde, M.; Bernoud-Hubac, N. The pleiotropic effects of omega-3 docosahexaenoic acid on the hallmarks of Alzheimer's disease. J. Nutr. Biochem. 2016, 38, 1-11. [CrossRef] [PubMed]

7. Burdge, G. $\alpha$-Linolenic acid metabolism in men and women: Nutritional and biological implications. Curr. Opin. Clin. Nutr. Metab. Care 2004, 7, 137-144. [CrossRef]

8. Thies, F.; Pillon, C.; Moliere, P.; Lagarde, M.; Lecerf, J. Preferential incorporation of sn-2 lysoPC DHA over unesterified DHA in the young rat brain. Am. J. Physiol. 1994, 267, R1273-R1279. [CrossRef]

9. Sugasini, D.; Thomas, R.; Yalagala, P.C.R.; Tai, L.M.; Subbaiah, P.V. Dietary docosahexaenoic acid (DHA) as lysophosphatidylcholine, but not as free acid, enriches brain DHA and improves memory in adult mice. Sci. Rep. 2017, 7, 11263. [CrossRef]

10. Chouinard-Watkins, R.; Chen, C.T.; Metherel, A.H.; Lacombe, R.J.S.; Thies, F.; Masoodi, M.; Bazinet, R.P. Phospholipid class-specific brain enrichment in response to lysophosphatidylcholine docosahexaenoic acid infusion. Biochim. Biophys. Acta Mol. Cell Biol. Lipids 2017, 1862, 1092-1098. [CrossRef]

11. Bazinet, R.P.; Bernoud-Hubac, N.; Lagarde, M. How the plasma lysophospholipid and unesterified fatty acid pools supply the brain with docosahexaenoic acid. Prostaglandins Leukot. Essent. Fatty Acids 2019, 142, 1-3. [CrossRef]

12. Bernoud, N.; Fenart, L.; Molière, P.; Dehouck, M.-P.; Lagarde, M.; Cecchelli, R.; Jecerf, J. Preferential Transfer of 2-Docosahexaenoyl-1-Lysophosphatidylcholine Through an In Vitro Blood-Brain Barrier Over Unesterified Docosahexaenoic Acid. J. Neurochem. 1999, 72, 338-345. [CrossRef]

13. Nguyen, L.N.; Ma, D.; Shui, G.; Wong, P.; Cazenave-Gassiot, A.; Zhang, X.; Silver, D.L. Mfsd2a is a transporter for the essential omega-3 fatty acid docosahexaenoic acid. Nature 2014, 509, 503-506. [CrossRef] [PubMed]

14. Thies, F.; Delachambre, M.C.; Bentejac, M.; Lagarde, M.; Lecerf, J. Unsaturated fatty acids esterified in 2-acyl-1-lysophosphatidylcholine bound to albumin are more efficiently taken up by the young rat brain than the unesterified form. J. Neurochem. 1992, 59, 1110-1116. [CrossRef] [PubMed]

15. Croset, M.; Brossard, N.; Polette, A.; Lagarde, M. Characterization of plasma unsaturated lysophosphatidylcholines in human and rat. Biochem. J. 2000, 345, 61-67. [CrossRef] [PubMed]

16. Polette, A.; Deshayes, C.; Chantegrel, B.; Croset, M.; Armstrong, J.M.; Lagarde, M. Synthesis of acetyl,docosahexaenoyl-glycerophosphocholine and its characterization using nuclear magnetic resonance. Lipids 1999, 34, 1333-1337. [CrossRef] [PubMed]

17. Chauveau, F.; Cho, T.H.; Perez, M.; Guichardant, M.; Riou, A.; Aguettaz, P.; Picq, M.; Lagarde, M.; Berthezène, Y.; Nighoghossian, N.; et al. Brain-targeting form of docosahexaenoic acid for experimental stroke treatment: MRI evaluation and anti-oxidant impact. Curr. Neurovasc. Res. 2011, 8, 95-102. [CrossRef] [PubMed]

18. Hachem, M.; Géloën, A.; Van, A.L.; Foumaux, B.; Fenart, L.; Gosselet, F.; Da Silva, P.; Breton, G.; Lagarde, M.; Picq, M.; et al. Efficient Docosahexaenoic Acid Uptake by the Brain from a Structured Phospholipid. Mol. Neurobiol. 2016, 53, 3205-3215. [CrossRef] [PubMed]

19. Fourrier, C.; Remus-Borel, J.; Greenhalgh, A.D.; Guichardant, M.; Bernoud-Hubac, N.; Lagarde, M.; Joffre, C.; Layé, S. Docosahexaenoic acid-containing choline phospholipid modulates LPS-induced neuroinflammation in vivo and in microglia In Vitro. J. Neuroinflamm. 2017, 14, 170. [CrossRef]

20. Lo Van, A.; Sakayori, N.; Hachem, M.; Belkouch, M.; Picq, M.; Fourmaux, B.; Lagarde, M.; Osumi, N.; Bernoud-Hubac, N. Targeting the Brain with a Neuroprotective Omega-3 Fatty Acid to Enhance Neurogenesis in Hypoxic Condition in Culture. Mol. Neurobiol. 2019, 56, 986-999. [CrossRef]

21. Lagarde, M.; Bryon, P.A.; Guichardant, M.; Dechavanne, M. A simple and efficient method for platelet isolation from their plasma. Thromb. Res. 1980, 17, 581-588. [CrossRef]

22. Gabert, L.; Vors, C.; Louche-Pélissier, C.; Sauvinet, V.; Lambert-Porcheron, S.; Drai, J.; Michalski, M.C. ${ }^{13}$ C tracer recovery in human stools after digestion of a fat-rich meal labelled with $\left[1,1,1-{ }^{13} \mathrm{C} 3\right]$ tripalmitin and [1, 1, 1-13 C3]triolein. Rapid Commun. Mass Spectrom. RCM 2011, 25, 2697-2703. [CrossRef] [PubMed]

23. Brossard, N.; Croset, M.; Normand, S.; Pousin, J.; Lecerf, J.; Laville, M.; Tayot, J.L.; Lagarde, M. Human plasma albumin transports $\left[{ }^{13} \mathrm{C}\right]$ docosahexaenoic acid in two lipid forms to blood cells. J. Lipid Res. 1997, 38, 1571-1582. [PubMed] 
24. Lemaitre-Delaunay, D.; Pachiaudi, C.; Laville, M.; Pousin, J.; Armstrong, M.; Lagarde, M. Blood compartmental metabolism of docosahexaenoic acid (DHA) in humans after ingestion of a single dose of $\left[{ }^{13} \mathrm{C}\right] \mathrm{DHA}$ in phosphatidylcholine. J. Lipid Res. 1999, 40, 1867-1874. [PubMed]

25. Connor, W.E.; Neuringer, M.; Lin, D.S. Dietary effects on brain fatty acid composition: The reversibility of n-3 fatty acid deficiency and turnover of docosahexaenoic acid in the brain, erythrocytes, and plasma of rhesus monkeys. J. Lipid Res. 1990, 31, 237-247.

26. Létondor, A.; Buaud, B.; Vaysse, C.; Fonseca, L.; Herrouin, C.; Servat, B.; Layé, S.; Pallet, V.; Alfos, S. Erythrocyte DHA level as a biomarker of DHA status in specific brain regions of $n-3$ long-chain PUFA-supplemented aged rats. Br. J. Nutr. 2014, 112, 1805-1818. [CrossRef]

27. Acetyl,2acyl-Glycerophosphocholines for the Treatment of Inflammation or of Intestinal Cancer. Patent WO 2017/006047 Al, 12 January 2017.

(C) 2020 by the authors. Licensee MDPI, Basel, Switzerland. This article is an open access article distributed under the terms and conditions of the Creative Commons Attribution (CC BY) license (http://creativecommons.org/licenses/by/4.0/). 